\title{
Seleção de clones de palma forrageira resistentes à cochonilha-do-carmim (Dactylopius sp)
}

\section{Andréa Guimarães Vieira de Vasconcelos ${ }^{1}$, Mario de Andrade Lira ${ }^{2}$, Vanildo Leal Bezerra Cavalcanti ${ }^{2}$, Mércia Virginia Ferreira dos Santos $^{3}$, Lilia Willadino ${ }^{3}$}

\footnotetext{
${ }^{1}$ Banco do Nordeste do Brasil.

2 IPA.

${ }^{3}$ Universidade Federal Rural de Pernambuco.
}

RESUMO - Visando selecionar clones de palma forrageira resistentes à cochonilha-do-carmim, realizou-se um experimento em casa de vegetação no período de setembro de 2001 a janeiro de 2002. A partir de infestação artificial com a cochonilha, foram testados 20 clones de palma forrageira, em delineamento inteiramente casualizado, com quatro repetições. Foram observadas a fixação de colônias sobre os cladódios e a porcentagem de cladódios infestados, por meio de uma escala de notas variando de 0 a 5 . Os clones que apresentaram maior resistência ao ataque da praga foram Miúda e Orelha de Elefante.

Palavras-chave: Hemiptera, palma doce, praga, semi-árido

\section{Selection of prickly-pear clones resistant to carmine cochineal Dactylopius sp}

ABSTRACT - The experiment was carried out in a greenhouse from September 2001 to January 2002 to select several prickly-pear varieties resistant to cochineal carmine. Twenty pricky-pear varieties were evaluated as a completely randomized experimental design with four replicates. The plants were artificially infested. The infestation level was evaluated by a 0 - 5 scale. The most resistants clone are "Miúda" and "Orelha de Elefante".

Key Words: Hemiptera, honey prickly-pear, plague, semi-arid

\section{Introdução}

Existe na região semiárida déficit qualitativo e quantitativo na produção de forragens, o que prejudica a produtividade animal. A palma forrageira (Opuntia e Nopalea) é um alimento importante na atividade pecuária por ser adaptada às condições climáticas da região e poder alcançar produtividade de até 40 toneladas de matéria seca por hectare por colheita (Santos et al., 2006).

Nos últimos anos, tem-se observado redução na produtividade da cultura, causada pelo ataque de pragas e patógenos. Ainda são escassas as informações sobre aspectos biológicos das principais pragas e doenças e seus controles (Pimienta Barrios \& Munoz-Uriaz, 2001).

A cochonilha do carmim é uma das diversas espécies do gênero Dactylopius que produzem o corante carmim. Essas espécies são criadas em cactáceas e podem se transformar em pragas se a cultura não for conduzida tecnicamente ou se forem disseminadas livremente nas plantas cultivadas (Waruby et al., 2005). Ataques desta cochonilha em palma cultivada foram observados nos estados de Alagoas, Pernambuco, Paraíba, Rio Grande do Norte e Ceará (Santos et al., 2006).

No processo de alimentação, as cochonilhas sugam as raquetes da palma inoculando toxinas, o que resulta no enfraquecimento das plantas, provocando o amarelecimento e a queda dos cladódios. Em ataques mais severos, quando não é adotada medida de controle, podem ocorrer a morte da planta e a destruição do palmal (Cavalcanti et al., 2001).

$\mathrm{Na}$ literatura, não são encontrados estudos sobre controle biológico para essa praga. O controle químico, por seu elevado custo e suas possíveis implicações ambientais, torna-se difícil, principalmente em virtude das condições sócio-econômicas dos pequenos produtores rurais.

Dessa forma, a melhor alternativa de cultivo para a palma em regiões atacadas por esse inseto é o plantio de clones resistentes. Essa alternativa destaca-se como estratégia ideal de controle de pragas, pois sua utilização reduz a população do inseto a níveis toleráveis; tem efeito cumulativo e persistente; não é poluente; não acarreta ônus ao 
sistema de produção e não exige conhecimentos específicos dos agricultores para sua utilização (Lara, 1991).

Assim, avaliou-se neste trabalho a resistência de clones de palma forrageira a cochonilha do carmim.

\section{Material e Métodos}

O experimento de seleção dos clones de palma forrageira foi conduzido na sede do Instituto Agronômico de Pernambuco - IPA, em Recife, no período de setembro de 2001 a fevereiro de 2002. Foram utilizados cladódios terciários com aproximadamente 2 anos de idade de 20 clones de palma forrageira provenientes da Estação Experimental de Caruaru, do IPA. Entre os clones (Tabela 1), encontram-se as variedades de palma mais cultivadas no estado (Gigante, Redonda, Miúda, Clone IPA-20), outras do programa de melhoramento do IPA, além de clones promissores importados do México pelo IPA e da África, pelo CPATSA (Centro de Pesquisa Agropecuária do Trópico Semi-Árido).

Os clones foram cultivados em canteiros de $1,20 \times 0,40$ $\times 15,0 \mathrm{~m}$, em telado, utilizando-se para plantio um cladódio por cova. O telado, fechado na parte superior e nas laterais, por sombrite, possibilitou a entrada da água das chuvas durante o período do experimento. O solo utilizado foi proveniente da Estação Experimental do IPA, em Caruaru, e apresentou as seguintes características químicas: $\mathrm{pH}=6,78 ; \mathrm{P}=>40 \mathrm{mh} / \mathrm{dm}^{3} ; \mathrm{Ca}=8,45 \mathrm{cmolc} / \mathrm{dm}^{3} ; \mathrm{Mg}=$ $4,85 \mathrm{cmolc} / \mathrm{dm}^{3} ; \mathrm{Na}=0,12 \mathrm{cmolc} / \mathrm{dm}^{3} ; \mathrm{K}=0,35 \mathrm{cmolc} / \mathrm{dm}^{3}$; $\mathrm{Al}=0,10 \mathrm{cmolc} / \mathrm{dm}^{3} ; \mathrm{H}=2,12 \mathrm{cmolc} / \mathrm{dm}^{3} ; \mathrm{S}=13,8 \mathrm{cmolc} / \mathrm{dm}^{3}$; CTC $=16,0 \mathrm{cmolc} / \mathrm{dm}^{3} ; \mathrm{V}=86 \%$.

Visando controlar possíveis infestações de patógenos, o solo foi tratado com solução do fungicida Benlate a $2 \%$ duas semanas antes do plantio dos cladódios. O plantio foi realizado em covas, com aproximadamente $20 \mathrm{~cm}$ de profundidade e com espaçamento de 0,50 × 0,50 m. Após 90 dias de plantio, os cladódios foram infestados artificialmente

Tabela 1 - Clones de palma forrageira avaliados quanto à resistência a cochonilha do carmim

\begin{tabular}{lccc}
\hline No & Clone & No & Clone \\
\hline 1 & Gigante & 11 & IPA - 90-115 \\
2 & Miúda & 12 & IPA - 90 - 156 \\
3 & Redonda & 13 & 1258 - Additional C.V. \\
4 & Clone IPA-20 & 14 & Orelha de elefante \\
5 & IPA - $90-18$ & 15 & 1278 - Mexico Fodder \\
6 & IPA - $90-73$ & 16 & $1294-$ Mexico Vegetable \\
7 & IPA - $90-75$ & 17 & $1311-$ Marmillon Fodder \\
8 & IPA - $90-92$ & 18 & 1317 - Chile Fruit \\
9 & IPA - $90-106$ & 19 & $1327-$ Marmillon Fodder \\
10 & IPA - $90-111$ & 20 & Algerian \\
\hline
\end{tabular}

por meio de fixação (com elástico) de pedaços de cladódios de palma forrageira contendo dez colônias do inseto em estágio de postura. A temperatura e umidade dentro do telado foram monitoradas diariamente durante todo o período experimental com auxílio de um termohigrógrafo e a precipitação foi medida por meio de pluviômetro.

Foram observadas a fixação de colônias sobre os cladódios e a porcentagem de cladódios infestados. A primeira avaliação foi realizada 8 dias após a infestação e as seguintes aos 20, 33 e 47 dias, atribuindo-se notas individuais de 0 a 5 (em que 0 = ausência de infestação; e 5 = infestação máxima) para todos os cladódios de cada planta, conforme metodologia adaptada de Silva (1991) (Tabela 2, Figura 1).

O delineamento experimental utilizado foi inteiramente casualizado, com quatro repetições, considerando a unidade experimental uma planta de cada clone. A nota de cada planta foi determinada pela média das notas obtidas individualmente em cada cladódio. Os dados foram submetidos a análise de variância (ANOVA) para comprovação de diferenças significativas entre as médias dos clones.

Os dados analisados correspondem às notas individuais de cada planta aos 47 dias e foram processados utilizando-se o programa estatístico SWNTIA 4.2.1 (EMBRAPA, 1996), de modo que as médias foram comparadas pelo teste Duncan a 5\% de probabilidade. Foram ajustadas equações de regressão para cada clone, de modo que o número de dias pós-infestação foi a variável independente e o nível da infestação, a variável dependente.

Com o objetivo de comprovar o não-desenvolvimento do inseto em cladódios nas plantas consideradas resistentes, realizou-se um teste de confirmação. Este teste consistiu plantio de dois cladódios dos clones mais resistentes, identificados no experimento principal, em caixas plásticas contendo o mesmo solo do experimento anterior. Esse teste foi realizado em casa de vegetação na sede do IPA em Recife. As caixas foram colocadas sobre bancadas da

Tabela 2 - Escala de notas utilizada na avaliação de clones de palma forrageira infestados com cochonilha Dactylopius sp (Hemiptera, Dactylopiidae)

\begin{tabular}{ll}
\hline Nota & \multicolumn{1}{c}{ Nível de infestação } \\
\hline 0 & Ausência de cochonilha sobre o cladódio \\
1 & Até 10 colônias por cladódio \\
2 & 11 a 40 colônias por cladódio \\
3 & 41 a 80 colônias por cladódio \\
4 & 81 a 120 colônias por cladódio \\
5 & Mais de 120 colônias por cladódio \\
\hline
\end{tabular}



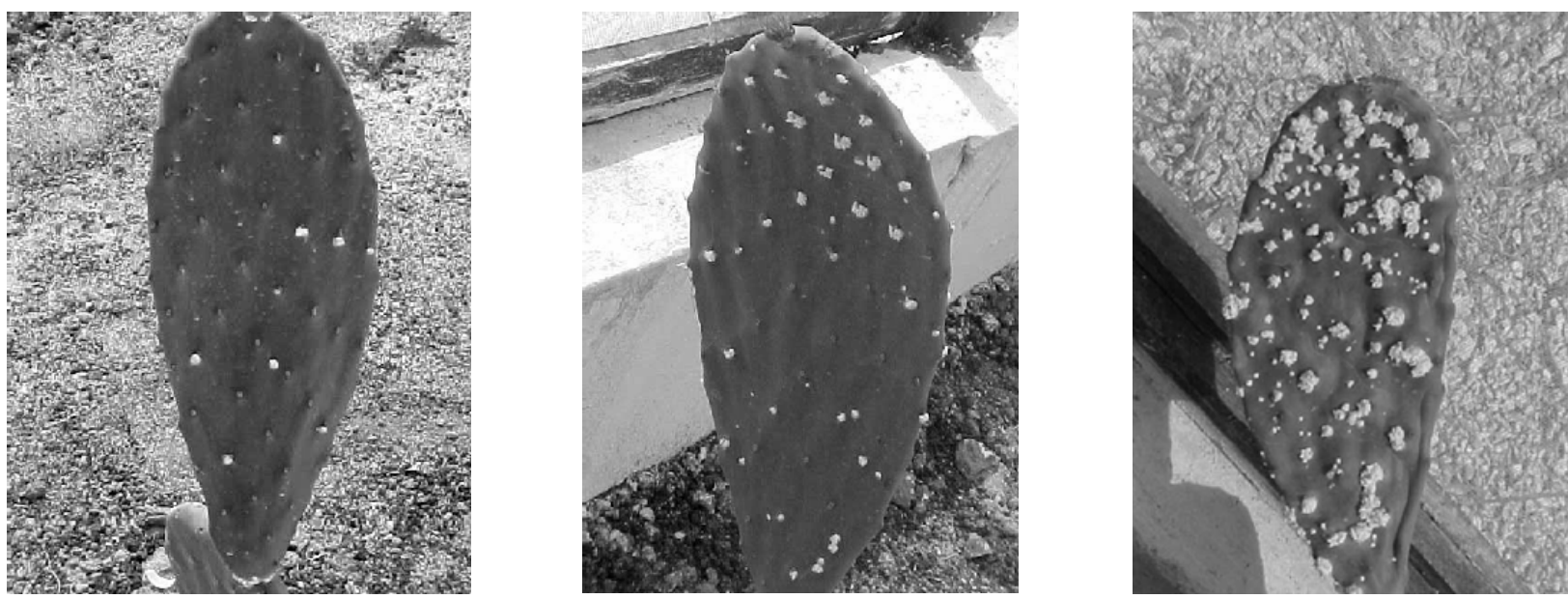

Figura 1 - Cladódios de palma forrageira, representando as notas 1, 3 e 5 (esquerda para direita), conforme escala utilizada na avaliação da infestação por cochonilha do carmim.

casa de vegetação. No mesmo local, foram colocados baldes contendo um cladódio do clone Gigante, considerado susceptível durante o primeiro experimento. A infestação artificial dos cladódios foi realizada 45 dias após o plantio, de forma semelhante ao experimento realizado nos canteiros do telado. As avaliações quanto à fixação das ninfas sobre os cladódios foram realizadas quinzenalmente, durante 60 dias, utilizando-se o mesmo procedimento do experimento anterior.

\section{Resultados e Discussão}

A umidade manteve-se alta durante o experimento (Tabela 3), com média de 98\%, no período noturno. De acordo com Flores-Flores \& Tekelenburg (2001), alta umidade relativa afeta a duração do ciclo biológico do inseto, sobretudo se acompanhada de baixas temperaturas: nas fêmeas, aumenta o período de pré-oviposição e, nos machos, alonga o ínstar de pré-pupa e pupa. Sabe-se que a chuva afeta o desenvolvimento do inseto e aumenta a taxa de mortalidade das ninfas, que pode chegar a $98 \%$ (Flores-Flores \& Tekelenburg, 2001). Apesar de o experimento ter sido realizado na época seca do ano, foi constatada precipitação de $458,5 \mathrm{~mm}$ durante todo o período experimental. As chuvas se concentraram no final do experimento, por isso, não comprometeram a fixação dos insetos sobre os cladódios.

A infestação pela cochonilha-do-carmim apresentou grande variação entre os clones estudados, com notas variando de 0 a 4,74 (Tabela 4). Os clones cv. Miúda e Orelha de Elefante apresentaram notas mais baixas e foram seguidos pelo clone Algerian. A fixação das ninfas sobre os cladódios ocorreu de forma ascendente, dos cladódios primários para os secundários, até atingir os cladódios mais extremos. Os insetos se fixaram nas partes mais sombreadas dos cladódios, colonizando inicialmente as junções entres os cladódios e em volta das auréolas.

A análise de variância indicou média geral de 3,30 com coeficiente de variação de $16,14 \%$. O teste Duncan foi o que permitiu melhor identificação de diferenças significativas entre os clones avaliados em comparação a outros testes de comparação de médias. De acordo com Lara (1991), existem diferentes graus de resistência, que variam de acordo com a resposta da planta ao ataque do inseto. Assim, as plantas podem ser classificadas como: imunes; altamente resistentes; com resistência moderada; susceptíveis ou altamente susceptíveis. O clone Miúda pode ser considerado imune, pois não permitiu o desenvolvimento do inseto. Os clones Orelha de Elefante e Algerian, com notas 0,25 e 1,66, respectivamente, podem ser considerados altamente resistentes, com nenhum ou poucos cladódios infestados. Todos os demais clones, que apresentaram infestação superior a 3, foram considerados susceptíveis a altamente susceptíveis.

É possível que os clones Miúda e Orelha de Elefante tenham apresentado uma resistência classificada como antibiose, que ocorre quando a planta tem efeito adverso sobre a biologia do inseto, provocando, por exemplo, morte das ninfas, morte durante a transformação para outras fases, alteração do tempo de vida ou impedimento de reprodução (Lara, 1991). Constatou-se, por observações in loco, que os insetos não se fixaram sobre os cladódios do clone Miúda e, no cladódio de Orelha de Elefante, apesar da fixação, não se reproduziram. 
Tabela 3 - Temperatura, umidade relativa e precipitação média durante o período experimental

\begin{tabular}{lccccc}
\hline & Setembro & Outubro & Novembro & Dezembro & Janeiro \\
\hline Precipitação (mm) & 87,6 & 97,9 & 28,8 & 51,0 & 193,2 \\
Temperatura média & $27^{\circ} \mathrm{C}$ & $28^{\circ} \mathrm{C}$ & $27^{\circ} \mathrm{C}$ & $27^{\circ} \mathrm{C}$ & $25^{\circ} \mathrm{C}$ \\
Temperatura mínima & $22^{\circ} \mathrm{C}$ & $23^{\circ} \mathrm{C}$ & $23^{\circ} \mathrm{C}$ & $33^{\circ} \mathrm{C}$ & $20^{\circ} \mathrm{C}$ \\
Temperatura máxima & $31^{\circ} \mathrm{C}$ & $35^{\circ} \mathrm{C}$ & $79,0 \%$ & $86,3 \%$ & $86,5 \%$ \\
Umidade média & $75,0 \%$ & $76,5 \%$ & $55,0 \%$ & $60 \%$ & $99 \%, 0 \%$ \\
Umidade mínima & $55,0 \%$ & $60,0 \%$ & $98,0 \%$ & $99 \%$ \\
Umidade máxima & $95,0 \%$ & $98,0 \%$ & & & $99 \%, 0 \%$ \\
\hline
\end{tabular}

Tabela 4 - Incidência de cochonilha do carmin em clones de palma 47 dias após infestação

\begin{tabular}{ll}
\hline Clone & Nota \\
\hline Cv. Redonda & $4.470000 \mathrm{a}$ \\
IPA - $90-73$ & $4.156667 \mathrm{ab}$ \\
Clone IPA 20 & $4.092500 \mathrm{ab}$ \\
IPA - $90-92$ & $4.020000 \mathrm{ab}$ \\
1327 Marmillon fodder & $3.967500 \mathrm{ab}$ \\
IPA - $90-111$ & $3.905000 \mathrm{ab}$ \\
IPA - 90 - 18 & $3.892500 \mathrm{ab}$ \\
1317 Chile Fruit & $3.750000 \mathrm{ab}$ \\
IPA - 90 - 75 & $3.690000 \mathrm{ab}$ \\
IPA - 90 - 156 & $3.665000 \mathrm{ab}$ \\
IPA - 90 -115 & $3.652500 \mathrm{ab}$ \\
IPA - 90 -106 & $3.597500 \mathrm{ab}$ \\
1278 Mexico Fodder & $3.505000 \mathrm{~b}$ \\
1311 Marmillon Fodder & $3.417500 \mathrm{~b}$ \\
1258 Additional C.V. & $3.375000 \mathrm{~b}$ \\
1294 Mexico Vegetable & $3.250000 \mathrm{~b}$ \\
Cv. Gigante & $3.250000 \mathrm{~b}$ \\
Algerian & $1.667500 \mathrm{c}$ \\
Orelha de elefante & $0.250000 \mathrm{~d}$ \\
Cv. Miúda - Nopalea cochonellifera & $0.000000 \mathrm{~d}$ \\
\hline
\end{tabular}

Notas seguidas de letras diferentes diferem entre si pelo teste Duncan a 5\% de probabilidade.

Outro tipo de resistência, classificado como nãopreferência, ocorre quando a planta é menos utilizada pelo inseto para alimentação, oviposição ou abrigo em comparação a outra em condições idênticas (Lara, 1991). Como o trabalho foi realizado em condições de igualdade, alguns clones apresentaram esse tipo de resistência, como o Algerian.

A análise de regressão indicou que o nível de infestação apresentou, com o passar do tempo, regressão do tipo linear em todos os clones, com exceção de Miúda, Orelha de Elefante e Algerian (Tabela 5).

Uma vez que no cultivar Miúda ( $\hat{Y}=0$ ) não houve infestação, não foi possivel estabelecer uma equação. $\mathrm{O}$ cultivar Orelha de Elefante apresentou nota zero aos 8 e 20 dias e 0,25 aos 33 e 47 dias e esse resultado foi ajustado a uma equação polinomial. O cultivar Algerian, por sua vez, apresentou equação do tipo exponencial, o que indica baixo nível de infestação nas três primeiras observações e esse nível de infestação cresceu exponencialmente com o passar do tempo, o que poderia quebrar a resistência caso o experimento tivesse duração mais prolongada.
Tabela 5 - Equação de regressão para os clones que apresentaram infestação no intervalo de 8 e 47 dias

\begin{tabular}{lccc}
\hline Clone & Regressão & Equação de regressão & $\mathrm{R}^{2}$ \\
\hline 1 & Linear & $\hat{\mathrm{Y}}=0,0424 \mathrm{x}+1,1469$ & 0,9560 \\
3 & Linear & $\hat{\mathrm{Y}}=0,0529 \mathrm{x}+1,8022$ & 0,9497 \\
4 & Linear & $\hat{\mathrm{Y}}=0,059+1,1207$ & 0,9526 \\
5 & Linear & $\hat{\mathrm{Y}}=0,061 \mathrm{x}+0,8432$ & 0,9636 \\
6 & Linear & $\hat{\mathrm{Y}}=0,0637 \mathrm{x}+0,8732$ & 0,9187 \\
7 & Linear & $\hat{\mathrm{Y}}=0,484 \mathrm{x}+1,3469$ & 0,9740 \\
8 & Linear & $\hat{\mathrm{Y}}=0,0706 \mathrm{x}+0,5450$ & 0,9792 \\
9 & Linear & $\hat{\mathrm{Y}}=0,0427 \mathrm{x}+1,5797$ & 0,9993 \\
10 & Linear & $\hat{\mathrm{Y}}=0,0571 \mathrm{x}+1,0388$ & 0,9490 \\
11 & Linear & $\hat{\mathrm{Y}}=0,0635 \mathrm{x}+0,6215$ & 0,9955 \\
12 & Linear & $\hat{\mathrm{Y}}=0,0545 \mathrm{x}+1,1074$ & 0,9991 \\
13 & Linear & $\hat{\mathrm{Y}}=0,0589 \mathrm{x}+0,6437$ & 0,9983 \\
14 & Polinomial & $\hat{\mathrm{Y}}=-4 \mathrm{E}-05 \mathrm{x}+0,0099$ & 0,8020 \\
15 & Linear & $\hat{\mathrm{Y}}=0,0437 \mathrm{x}+1,3218$ & 0,9527 \\
16 & Linear & $\hat{\mathrm{Y}}=0,0396 \mathrm{x}+1,3371$ & 0,9787 \\
17 & Linear & $\hat{\mathrm{Y}}=0,0389 \mathrm{x}+1,6235$ & 0,9915 \\
18 & Linear & $\hat{\mathrm{Y}}=0,0691 \mathrm{x}+0,5080$ & 0,9957 \\
19 & Linear & $\hat{\mathrm{Y}}=0,056 \mathrm{x}+1,3349$ & 0,9998 \\
20 & Exponencial & $\hat{\mathrm{Y}}=0,3688 \mathrm{e} .0,0302 \mathrm{x}$ & 0,9636 \\
\hline & & & \\
14 & & & \\
14 & & &
\end{tabular}

No teste de confirmação de resistência, no qual foram plantados os clones Miúda e Orelha de Elefante, constatou-se resistência desses clones a cochonilha-do-carmim, pois não houve fixação de nenhuma colônia sobre os cladódios plantados. As colônias presentes nos cladódios do cultivar Gigante, utilizado como controle, desenvolveram-se nas condições em que foram mantidas. Assim, ficou descartada a possibilidade de efeito das condições ambientais da casa de vegetação sobre a não-fixação das colônias nos clones selecionados.

As variedades de palma forrageira mais difundidas no Nordeste são a Redonda, a Gigante e a Miúda. As variedades Redonda e Gigante (Opuntia ficus-indica) são reconhecidamente mais resistentes à seca e mais produtivas e, por 
esses motivos, são as mais cultivadas. Por outro lado, essas variedades foram identificadas como as mais sensíveis ao ataque da cochonilha do carmim, o que demonstra fragilidade na reserva estratégica de forragem em caso de disseminação desse inseto.

A variedade Miúda (Nopalea cochenillifera) tem melhor valor nutritivo em comparação à Redonda e à Gigante, contudo, apresenta menor produção de matéria verde. No entanto, como sua porcentagem de matéria seca é mais elevada, a produção final de matéria seca por área pode ser equiparada à das variedades Redonda e Gigante (Santos et al., 2001).

O cultivar Orelha de Elefante, por sua vez, é um clone importado e encontra-se em fase de testes para avaliação de seu desempenho agronômico. Esse cultivar apresenta espinhos, o que dificulta seu manejo como forrageira, no entanto, essa característica, apesar de ser indesejável na alimentação animal, garante a esta espécie maior resistência à seca, uma vez que os espinhos servem para reduzir a temperatura do caule durante o dia e sua presença diminui também a captação de luz pelo cladódio (Nobel, 1983).

\section{Conclusões}

Os clones de palma forrageira Miúda e Orelha de Elfante apresentam resistência à cochonilha-do-carmim Dactylopius sp., enquanto o clone Redonda é altamente suscetível.

\section{Agradecimentos}

Ao CNPq, pelas bolsas concedidas aos pesquisadores Mario de Andrade Lira, Mércia Virginia Ferreira dos Santos e Lilia Willadino. Aos colegas da Empresa Pernambucana de Pesquisa Agropecuária: Djalma Cordeiro dos Santos e Iderval Farias, membros do programa de melhoramento genético e manejo de palma forrageira, do qual foram obtidos os clones utilizados no experimento.

\section{Literatura Citada}

CAVALCANTI, V.A.L.B.; SENA, R.C.; COUTINHO, J.L.B. et al. Controle das cochonilhas da palma forrageira. Boletim IPA Responde, n.39, p.1-2, 2001.

EMPRESA BRASILEIRA DE PESQUISA E AGRIPECUÁRIA EMBRAPA - Centro Nacional de Pesquisa Tecnológica em Informática para Agricultura. SW NTIA, Versão 4.2.1, 3v Disquetes, Campinas: 1996.

FLORES-FLORES, V.; TEKELENBURG, A. Produção de corante Dacti (Dactylopius coccus Costa). In: IGLESES, P.; BARBERA, G.; BARRIOS, E.P. (Eds.) Agroecologia, cultivo e utilizações da palma forrageira. Roma: FAO, 1999. 216p. Co-editado pelo Sebrae-PB, João Pessoa, 2001.

LARA, F.M. Princípios de resistência de plantas a insetos. 2.ed. São Paulo: Ícone, 1991. 336p.

NOBEL, P.S. Spines influences on PAR interception, stem temperature and nocturnal acid accumulation. American Journal Botany, v.70, n.8, p.1244-1253, 1983.

PIMIENTA BARRIOS, E.; MUÑOZ-URIAZ, A. Domesticação das opuntias e variedades cultivadas. In: IGLESES, P.; BARBERA, G.; BARRIOS, E.P. (Eds.) Agroecologia, cultivo e utilizações da palma forrageira. Roma: FAO 1999. 216p. Co-editado pelo Sebrae-PB, João Pessoa, 2001.

SANTOS, D.C.; SANTOS, M.V.F.; FARIAS, I. et al. Desempenho produtivo de vacas 5/8 Holando/Zebu alimentadas com diferentes cultivares de palma forrageira (Opuntia e Nopalea). Revista Brasileira de Zootecnia, v.30, n.1, p.12-17, 2001.

SANTOS, D.C.; FARIAS, I.; LIRA, M.A. et al. Manejo e utilização da palma forrageira (Opuntia e Nopalea) em Pernambuco. Recife: Instituto Agronômico de Pernambuco, 2006. 48p. (Documentos, 30).

SILVA, S.Q. Avaliação do controle biológico da cochonilha de escamas da palma forrageira. 1991. 58f. Dissertação (Mestrado em Fitossanidade) - Universidade Federal Rural de Pernambuco, Recife, 1991.

WARUMBY, J.F.; ARRUDA FILHO, G.P.; CAVALCANTI, V.A.L.B. et al. Pragas da palma. In: MENEZES, R.S.C; SIMÕES, D.A.; SAMPAIO, E.V.S.B (Eds.). A palma no Nordeste do Brasil. 1.ed. Recife: UFPE; Editora Universitária, 2005. p.65-80. 